\title{
A Periadventitial Sirolimus-Releasing Mesh Decreased Intimal Hyperplasia in a Rabbit Model
}

\author{
I. SKALSKÝ ${ }^{1}$, E. FILOVÁ ${ }^{2,3}$, O. SZÁRSZOI ${ }^{1,3}$, M. PAŘÍZEK ${ }^{2,3}$, A. LYTVYNETS $^{2}$, \\ J. MALUŠKOVÁ ${ }^{1}$, A. LODEREROVÁ ${ }^{1}$, E. BRYNDA ${ }^{4}$, V. LISÁ ${ }^{2}$, Z. BURDÍKOVÁ ${ }^{2}$, \\ M. ČAPEK ${ }^{2}$, J. PIRK ${ }^{1,3}$, L. BAČÁKOVÁ ${ }^{2,3}$ \\ ${ }^{1}$ Institute for Clinical and Experimental Medicine, Prague, Czech Republic, ${ }^{2}$ Institute of Physiology, \\ Academy of Sciences of the Czech Republic, v.v.i., Prague, Czech Republic, ${ }^{3}$ Centre for \\ Cardiovascular Research, Prague, Czech Republic, ${ }^{4}$ Institute of Macromolecular Chemistry, \\ Academy of Sciences of the Czech Republic, v.v.i., Prague, Czech Republic
}

Received October 27, 2010

Accepted May 31, 2011

\begin{abstract}
Summary
Autologous vein grafts used as aortocoronary bypasses are often prone to intimal hyperplasia, which results in stenosis and occlusion of the vein. The aim of this study was to prevent intimal hyperplasia using a newly developed perivascular system with sustained release of sirolimus. This system of controlled drug release consists of a polyester mesh coated with a copolymer of L-lactic acid and $\varepsilon$-caprolactone that releases sirolimus. The mesh is intended for wrapping around the vein graft during surgery. The mesh releasing sirolimus was implanted in periadventitial position onto arteria carotis communis of rabbits, and neointimal hyperplasia was then assessed. We found that implanted sirolimus-releasing meshes reduced intima thickness by $47 \pm 10 \%$ compared to a vein graft after 3 weeks. The pure polyester mesh decreased vein intima thickness by $35 \pm 9 \%$. Thus, our periadventitial system for controlled release of sirolimus prevented the development of intimal hyperplasia in autologous vein grafts in vivo in rabbits. A perivascularly applied mesh releasing sirolimus is a promising device for preventing stenosis of autologous vein grafts.
\end{abstract}

\section{Key words}

Stenosis - Intimal hyperplasia - Controlled drug release • Perivascular mesh • Rapamycin

\section{Corresponding author}

Elena Filová, Dept. of Growth and Differentiation of Cell Populations, Institute of Physiology, Academy of Sciences of the Czech Republic, Videnska 1083, CZ-142 20 Prague 4 - Krc, Czech Republic. Fax: +420 24106 2488. E-mail: filova@biomed.cas.cz
Autologous saphenous vein is widely used as a conduit to solve the problem of stenosis or occlusion of the coronary and femoral arteries due to atherosclerotic lesions. The surgical outcome of these procedures has improved remarkably thanks to the use of alternative conduits (e.g. autologous arterial grafts, artificial synthetic grafts), but the saphenous vein is still used in coronary artery bypass grafting (CABG) and infrainguinal bypass graft surgery (Motwani and Topol 1998). The long-term patency of the vein graft likely depends on adequate adaptation into the arterial vascular system as well as relative moderation in the development of intimal hyperplasia. Neointimal hyperplasia, which develops immediately after grafting, is the most important early change in the grafted vein. Remodelling of autologous vessels after bypass surgery is characterised by damage to the endothelial cell layer and exposure of vascular smooth muscle cells (VSMC) on the luminal surface, which causes adhesion and aggregation of platelets, adhesion of monocytes, activation of migration and proliferation of VSMC, and also the attachment of regenerating endothelial cells (EC). In order to prevent autologous vascular graft remodelling, it is essential to support the endothelialization process, and to reduce the proliferation of VSMC.

Endothelialization of the graft is completed within several weeks after surgery (Liuzzo et al. 2005). Stents are usually inserted into autologous graft stenosis 
to solve the graft lumen patency. In order to prevent VSMC proliferation and graft restenosis, antiproliferative drug-eluting stents have been developed, such as sirolimus-eluting stents (CypherTM, Cordis J\&J, NJ), and paclitaxel-eluting stents (Colombo and Iakovou 2004).

Another way to influence neointimal formation is by an access from the adventitial surface of the grafted vessel. Periadventitial delivery of drugs from matrices placed adjacent to implanted grafts has been successfully used in animal models. Sirolimus was selected because previous studies had confirmed the ability of the drug to prevent neointimal hyperplasia with respect to its release kinetics, effective dosage, and safety in clinical practice (Schachner et al. 2004, Suzuki et al. 2001).

In our previous in vitro study, a periadventitial system of sustained release of sirolimus was developed (Filova et al. 2011). The system was constructed in the form of a polyester mesh (PES mesh) coated with copolymer of poly(L-lactic acid) and poly(e-caprolactone) with dissolved sirolimus (Fig. 1). We observed relatively quick release of sirolimus from the mesh into the phosphate-buffered saline; $68 \pm 6 \%$ of sirolimus was released within 11 days (Filova et al. 2011). Both the mesh and the copolymer ensured appropriate mechanical properties of the sheet, especially its strength, firmness, and the flexibility necessary for handling and the ability to be sutured. The results showed that the periadventitial copolymer-based system assured sustained release of antiproliferative drug sirolimus for 6 weeks. Sustained release of sirolimus suppresses VSMC proliferation for the time necessary for re-endothelialisation of the graft. This should reduce autologous graft remodelling and the need for subsequent treatment.

Wrapping the autologous graft with our polymeric sirolimus-releasing system ensures that the endothelial cell layer will be affected less than in the case of intravascular stents tightly touching the endothelium. Wrapping the vessel also can prevent mechanical strain on the graft induced by the stent (Jeremy et al. 2004). In addition, positive effects of external wall support on reducing vessel wall stress and inhibition of neointimal proliferation can be expected (Krejca et al. 2002).

The aim of this study was to evaluate the dynamics of the intimal changes in interposed external jugular vein grafts after three weeks. We hypothesize that this periadventitial sirolimus-releasing system wrapped around the autotransplanted vein will be a suitable option for positively influencing intimal hyperplasia and the patency of the vein graft.

A polyester mesh (PES mesh) (CHS 50, VUP Joint-Stock Company, Brno, bursting strength $138.0 \mathrm{~N}$, EN 12332-1 standard) was coated with a solution containing $5.2 \mathrm{mg}$ of sirolimus (Rapamycin, SigmaAldrich, Germany), $36.4 \mathrm{mg}$ of purasorb (Purasorb PLC 7015, a copolymer of L-lactic acid and $\varepsilon$-caprolactone, PURAC biomaterials) in $1 \mathrm{ml}$ of chlorbenzen - ethanol $(1.75: 1 \mathrm{v} / \mathrm{v})$; and dried. Then it was coated for a second time with the same solution and dried. The resulting impregnated mesh contained $0.14 \mathrm{mg}$ sirolimus per $\mathrm{cm}^{2}$. The dry mesh was sterilised with ethylene oxide.

Eighteen male Giant Chinchilla rabbits (3.0-3.5 $\mathrm{kg}$ ) were used in the experiments. Each experimental group included 4 to 8 animals, and the following experimental groups were tested: animals with an autologous graft ( 6 animals), animals with an autologous graft wrapped with a pure polyester mesh (4 animals), and animals with an autologous graft wrapped with the sirolimus-releasing mesh ( 8 animals). A rabbit model was used in the study as the mesh structure and mesh density were appropriate for the size of a rabbit jugular vein. Before surgery, the animals were anaesthetized using an intramuscular injection with ketamine hydrochloride $(30.0 \mathrm{mg} / \mathrm{kg})$. Anaesthesia was maintained with a mask and inhaled isoflurane (2.5-3.0 \%). Heparin (300 IU/kg) was administered intravenously to the animals. The operative procedure was performed using an aseptic technique. The right external jugular vein and the right common carotid artery were exposed. The vein bypass grafts were constructed using an anastomotic cuff technique and were implanted to the common carotid artery (Jiang et al. 2004). Finally, either a pure PES mesh or a sirolimus-releasing mesh was wrapped around the vein graft and fixed by polypropylene suture $8 / 0$ on the side. Non-wrapped autologous grafts were used as control samples. The animals were euthanized 3 weeks after implantation.

The explanted grafts were fixed in $10 \%$ formalin, embedded in paraffin, cut into 3-4 $\mu \mathrm{m}$ sections and stained with Van Gieson with elastica. The thickness of the intima was calculated from 32-84 measurements per rabbit using the MeasureStackLines plug-in module of Ellipse Software (ViDiTo Systems, Slovakia). The data is presented as mean \pm S.E.M. (Standard Error of Mean). One-way ANOVA and Scheffe's method of multiple comparison were used for the statistical analysis; the effect of drug presence was tested. A value of $p<0.05$ was considered to be significant. 


\section{dipcoating}

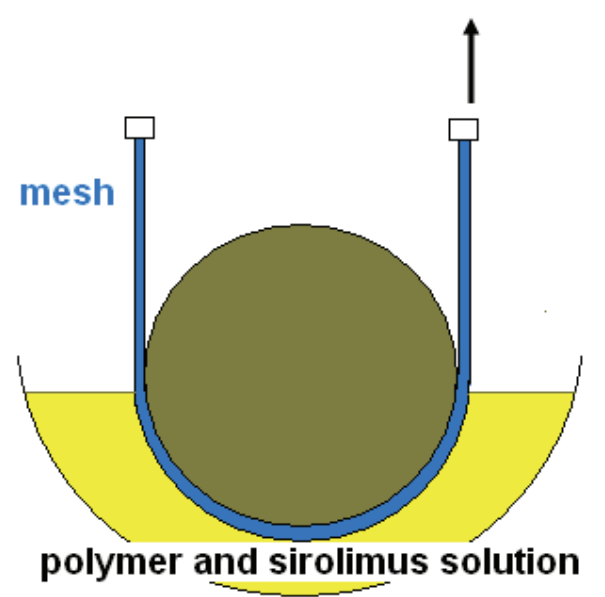

drying

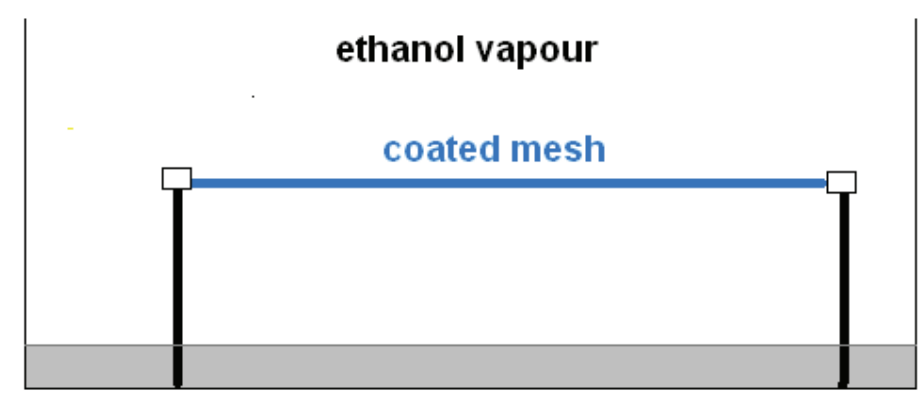

Fig. 1. The polyester mesh was passed through a solution of sirolimus, $5.2 \mathrm{mg}$, and purasorb, $36.4 \mathrm{mg}$, in $1 \mathrm{ml}$ chlorbenzen - ethanol $(1.75: 1 \mathrm{v} / \mathrm{v})$ and slowly dried in ethanol vapours.
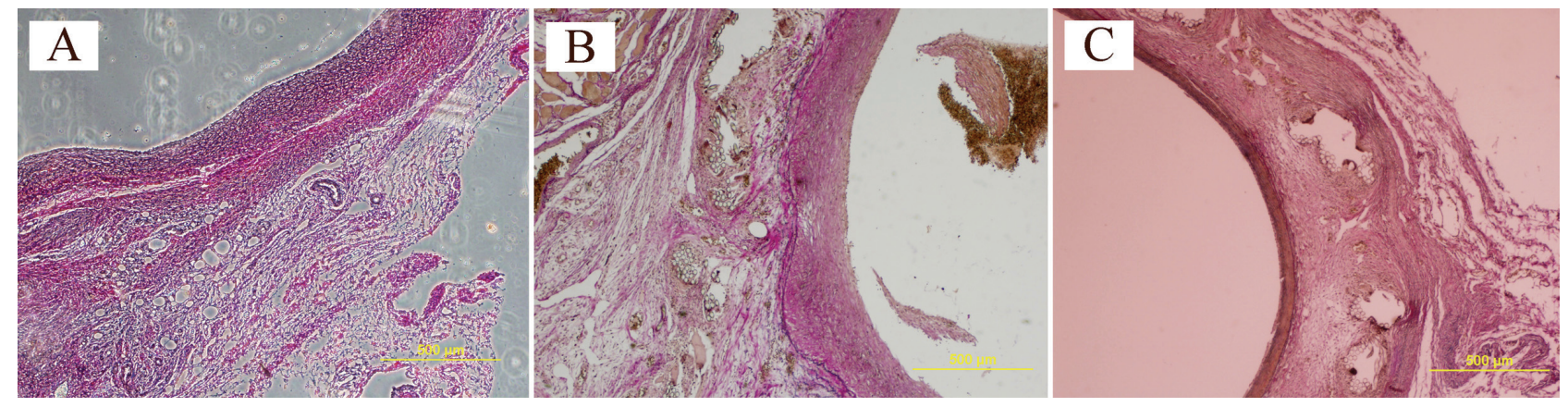

Fig. 2. An autologous vein graft (A), an autologous vein graft wrapped with a PES mesh (B), and an autologous vein graft wrapped with a PES mesh releasing sirolimus (C) after 3 weeks of implantation in rabbits, staining van Gieson and elastica, Olympus IX 51 microscope, objective $\times 4$, DP 70 digital camera, scale bar $=500 \mu \mathrm{m}$.

Histological staining revealed the presence of either a PES mesh or a sirolimus-releasing mesh in vein adventitia (Fig. 2), probably due to the graft expansion. The intima thickness in the controlled autologous grafts was $16.8 \pm 0.9 \mu \mathrm{m}$, in the autologous grafts wrapped with the pure PES mesh it was $11.0 \pm 0.4 \mu \mathrm{m}$, and in the autologous grafts wrapped with sirolimus-releasing mesh it was $8.9 \pm 0.2 \mu \mathrm{m}$. The decrease in intima thickness when the vein graft was wrapped with a pure PES mesh or a sirolimus-releasing mesh was by $35 \pm 10 \%$ or $47 \pm 9 \%$, respectively, compared to the autologous vein graft after three weeks; the difference was significant with a value of $p<0.001$ (Fig. 2). Sirolimus-releasing meshes had a significantly $(\mathrm{p}<0.05)$ stronger effect on reducing intimal hyperplasia than a pure PES mesh. No oblitering thrombi were found in any of the animals.

The copolymer purasorb loaded with sirolimus released sirolimus for several weeks to the vein graft tissue. We assume that the thickness of the vessel wall was low enough to enable diffusion of sirolimus into the tunica media to inhibit VSMC proliferation. Sirolimus penetration may also be supported by its hydrophobicity. A reduction of intimal hyperplasia dependent on the sirolimus dose was observed for stents containing 60$200 \mu \mathrm{g}$ of sirolimus (Suzuki et al. 2001). The effective concentration of sirolimus necessary for inhibiting VSMC proliferation is relatively low (from $\mathrm{ng} / \mathrm{ml}$ to $\mu \mathrm{g} / \mathrm{ml}$, Owen et al. 2010), allowing us to load the polymer with an amount of the drug sufficient for longterm release.

Our present study confirmed the hypothesis about the synergistic effect of a PES mesh and sirolimus on vein wall remodelling. The polyester periadventitial mesh probably worked in the same way as the external elastic membrane of the native arterial vessels, allowing them to withstand higher pressures in arterial circulation. While the release of sirolimus reduces intimal hyperplasia for a period of several weeks after implantation of the 
sirolimus-releasing PES mesh, the favourable elastic effect of the PES mesh itself can proceed even after the entire sirolimus load has been released.

It can be concluded that we created a unique periadventitial system with controlled release of antiproliferative drug sirolimus that reduced intimal hyperplasia in a rabbit model. This sirolimus-delivery system combines the positive effect of mechanical support from the wrap with the effect of the antiproliferative action of sirolimus. This system therefore represents a promising approach for preventing neointimal hyperplasia of vein grafts interposed into the arterial bed.

\section{Conflict of Interest}

There is no conflict of interest.

\section{Acknowledgements}

This study was supported by the Grant Agency of the Czech Ministry of Health (project No. NR9358), the Czech Science Foundation (projects No. 102/08/0691 and P108/11/0794), the Centre for Cardiovascular Research (project No. 1M6798582302) and research project AV0Z50110509. We also thank Mr. Zdeněk Plichta for mesh coating, Dr. V. Lánská for statistical analyses and Mr. Robin Healey (Czech Technical University in Prague) for his language revision of the manuscript.

\section{References}

COLOMBO A, IAKOVOU I: Drug-eluting stents: the new gold standard for percutaneous coronary revascularisation. Eur Heart J 25: 895-897, 2004.

EN 12332-1 (804629) Rubber- or plastics-coated fabrics. Determination of bursting strength. Steel ball method BritishAdopted European Standard / 15-Feb-1999 / 8 pages.

FILOVÁ E, PAŘIZZK M, OLŠOVSKÁ J, KAMENÍK Z, BRYNDA E, RIEDEL T, VANDROVCOVÁ M, LISÁ V, MACHOVÁ L, SKALSKÝ I, SZÁRSZOI O, SUCHÝ T, BAČÁKOVÁ L: Perivascular sirolimus-delivery system. Int J Pharm 404: 94-101, 2011.

JEREMY JY, BULBULIA R, JOHNSON JL, GADSDON P, VIJAYAN V, SHUKLA N, SMITH FCT, ANGELINI GD: A bioabsorbable (polyglactin), nonrestrictive, external sheath inhibits porcine saphenous vein graft thickening. J Thorac Cardiovasc Surg 127: 1766-1772, 2004.

JIANG Z, WU L, MILLER BL, GOLDMAN DR, FERNANDEZ CM, ABOUHAMZE ZS, OZAKI CK, BERCELI SA: A novel vein graft model: adaptation to differential flow environments. Am J Physiol Heart Circ Physiol 286: H240-H245, 2004.

KREJCA M, SKARYSZ J, SZMAGALA P, PLEWKA D, NOWACZYK G, PLEWKA A, BOCHENEK A: A new outside stent - does it prevent vein graft intimal proliferation? Eur J Cardiothorac Surg 22: 898-903, 2002.

LIUZZO JP, AMBROSE JA, COPPOLA JT: Sirolimus- and taxol-eluting stents differ towards intimal hyperplasia and re-endothelialization. $J$ Invasive Cardiol 17: 497-502, 2005.

MOTWANI JG, TOPOL EJ: Aortocoronary saphenous vein graft disease: pathogenesis, predisposition, and prevention. Circulation 97: 916-931, 1998.

OWEN SC, LI H, SANDERS WG, CHEUNG AK, TERRY CM: Correlation of tissue drug concentrations with in vivo magnetic resonance images of polymer drug depot around arteriovenous graft. J Control Release 146: 23-30, 2010.

SCHACHNER T, ZOU Y, OBERHUBER A, TZANKOV A, MAIRINGER T, LAUFER G, BONATTI JO: Local application of rapamycin inhibits neointimal hyperplasia in experimental vein grafts. Ann Thorac Surg 77: 1580-1585, 2004.

SUZUKI T, KOPIA G, HAYASHI S, BAILEY LR, LLANOS G, WILENSKY R, KLUGHERZ BD, PAPANDREOU G, NARAYAN P, LEON MB, YEUNG AC, TIO F, TSAO PS, FALOTICO R, CARTER AJ: Stent-based delivery of sirolimus reduced neointimal formation in a porcine coronary model. Circulation 104: 1188-1193, 2001. 